\title{
Anti-hepatotoxic activities of Hibiscus sabdariffa L. in animal model of streptozotocin diabetes-induced liver damage
}

\author{
David O Adeyemi ${ }^{1 *}$, Victor O Ukwenya ${ }^{2}$, Efere M Obuotor ${ }^{3}$ and Stephen O Adewole
}

\begin{abstract}
Background: Flavonoid-rich aqueous fraction of methanolic extract of Hibiscus sabdariffa calyx was evaluated for its anti-hepatotoxic activities in streptozotocin-induced diabetic Wistar rats.

Methods: Diabetes Mellitus was induced in Wistar rats by a single i.p injection of $80 \mathrm{mg} / \mathrm{kg}$ b.w. streptozotocin (STZ) dissolved in $0.1 \mathrm{M}$ citrate buffer (pH 6.3).

Results: The ameliorative effects of the extract on STZ-diabetes induced liver damage was evident from the histopathological analysis and the biochemical parameters evaluated in the serum and liver homogenates. Reduced levels of glutathione (GSH), catalase (CAT), superoxide dismutase (SOD), and glutathione peroxidase (GPx) $(3.76 \pm 0.38 \mu \mathrm{M}, 0.42 \pm 0.04 \mathrm{U} / \mathrm{L}, 41.08 \pm 3.04 \mathrm{U} / \mathrm{ml}, 0.82 \pm 0.04 \mathrm{U} / \mathrm{L}$ respectively) in the liver of diabetic rats were restored to a near normal level in the Hibiscus sabdariffa -treated rats $(6.87 \pm 0.51 \mu \mathrm{M}, 0.72 \pm 0.06 \mathrm{U} / \mathrm{L}$, $87.92 \pm 5.26 \mathrm{U} / \mathrm{ml}, 1.37 \pm 0.06 \mathrm{U} / \mathrm{L}$ respectively). Elevated levels of aspartate amino transferase (AST), alanine amino transferase (ALT) and alkaline phosphatase (ALP) in the serum of diabetic rats were also restored in Hibiscus sabdariffa -treated rats. Examination of stained liver sections revealed hepatic fibrosis and excessive glycogen deposition in the diabetic rats. These pathological changes were ameliorated in the extract-treated rats.
\end{abstract}

Conclusion: The anti-hepatotoxic activity of Hibiscus sabdariffa extract in STZ diabetic rats could be partly related to its antioxidant activity and the presence of flavonnoids.

Keywords: Liver, Toxicity, Diabetes mellitus, Hibiscus sabdariffa, Flavonoids, Antioxidant

\section{Background}

The liver plays a central and crucial role in the regulation of carbohydrate metabolism. Its normal functioning is essential for the maintenance of blood glucose levels and of a continued supply to organs that require a glucose energy source [1]. In addition, it has great capacity to detoxify toxic substances and synthesize useful ones. Therefore, the damage which is caused by hepatotoxic agents is of grave consequence to the body as it deprives the liver of its principal functions [2]. A significant amount of liver damage is induced by lipid peroxidation and other oxidative damages which are caused by the hepatotoxic chemicals $[3,4]$. It has been

\footnotetext{
* Correspondence: waledavade@yahoo.com

${ }^{1}$ Department of Anatomy and Cell Biology, Obafemi Awolowo University, Ile-Ife, Nigeria

Full list of author information is available at the end of the article
}

reported that liver injury caused by a variety of deleterious agents induces inflammation, necrosis, fibrosis cirrhosis and functional deteriorations [5].

Diabetes is a chronic disease with a relatively high prevalence in many populations across the world [6]. Diabetes is associated with several structural and functional liver abnormalities that affect glycogen and lipid metabolism [7-9]. Excess glycogen deposition, fibrosis, cirrhosis, steatohepatitis and Biliary disease in the liver has been reported in $55-80 \%$ of diabetic patients [10].

Plants used in traditional medicine for the treatment of liver disorders are of great interest, as they may serve as potential sources for new therapeutic agents that could be applied in the management and prevention of hepatic injuries. For example, plants rich in different phytochemical derivatives such as triterpenes, flavonoids 
or polyphenols, have been reported to exhibit antihepatotoxic effects in experimental liver-injury models induced by different types of hepatotoxicants, such as carbon tetrachloride, cadmium, galactosamine, acetaminophen and thioacetamide [11,12].

Hibiscus sabdariffa (HS) (family: Malvaceae) has been reported as an ethnomedicinal remedy for a variety of ailments including hypertension, hyperlipidaemia, obesity, diabetes, Jaundice liver and urinary problems [13]. It's antihypertensive [14,15] hypolipidaemic [16,17] anti-obesity $[18,19]$ and anti-hyperglycemic $[13,17]$ effects have been confirmed in man and experimental animals and the possible mechanisms have also been delineated. Water-soluble extracts from Hibiscus sabdariffa L. contain several antioxidants, such as protocatechuic acid [20] and anthocyanins [21,22]. Recent studies have shown the potentials of these antioxidants in the protection of liver in chemically-induced peroxidative liver damage [22-24]. Hence this study investigates the potential antihepatotoxic properties of the flavonoid-rich extract of Hibiscus sabdariffa in animal model of streptozotocin diabetes- induced liver damage.

\section{Methods}

Chemicals

All chemicals used were of analytical grade. STZ was purchased from Sigma-Aldrich (St. Louis, MO, USA) Biochemical kits for AST, ALT and ALP assay were purchased from Randox laboratory (Crumlin, Co. Antrim, UK); Biochemical kits for catalase, GSH, GPx and TBARS assay were purchased from Bio Assay System (Hayward, CA 94545 USA) while kit for SOD assay was purchased from Cell technology Inc (Mountain View, CA 94043). Other histological reagents and stains were purchased from Sigma-Aldrich (St. Louis, MO, USA).

\section{Animals}

Healthy Wistar rats (200 - 250 g) of either sex obtained from the animal holding facility of the College of Healthy Sciences, Obafemi Awolowo University Ile-Ife were used for the experiment. They were maintained under standard environmental conditions of temperature, humidity and light and fed on standard rat pellets (Ladokun feeds, Ibadan, Nigeria) and water ad libitum. The animals were acclimatized to the laboratory for four weeks prior to the start of the experiment. The rats received humane care according to the USA's National Institute of Health's Guide for the Care and Use of Laboratory Animals [25] and their experimental use was approved by the animal Ethics Committee of Obafemi Awolowo University Ile Ife.

\section{Experimental design}

The animals were randomly assigned into five groups $\mathrm{A}$, B, C, D and E of twelve rats each. Group A was normal control (normoglycemic rats), group B was test group I (normoglycemic rats treated with Hibiscus sabdariffa calyx extract (HSCE)); group $\mathrm{C}$ was diabetic negative control (untreated diabetic rats given STZ as described in "Induction of Experimental Diabetes" section); group D was test group II (diabetic rats treated with HSCE); while group $\mathrm{E}$ was diabetic positive control (diabetic rats treated with protamin zinc insulin).

\section{Plant material}

Matured calyxes of $H$. sabdariffa obtained from a local market in Ile-Ife, Nigeria were authenticated at the Forestry Research Institute of Nigeria (FRIN), Ibadan and a voucher specimen (FHI 107622) was submitted to the FRIN Herbarium for future reference.

\section{Extraction}

Dried and pulverized calyxes of $H$. sabdariffa (200 g) were extracted three times with $70 \%$ methanol (500 $\mathrm{mls} \times 3$ ) with continuous stirring at room temperature for 24 hours each. The extract was concentrated in vacuo at $25^{\circ} \mathrm{C}$ using a vacuum rotary evaporator (RE 100B, Bibby Sterilin, United Kingdom) and the aqueous phase was partitioned with ethyl acetate (EtOAc). The aqueous fraction (coded HSCE) was freeze dried using a vacuum freeze drier (FT33- Armfield, England) and used for the experiment. Solvent elimination under reduced pressure and subsequent freeze-drying gave $11.75 \mathrm{~g}$ (i. e., $5.875 \%$ yield) of a dark red, powdery extract.

\section{Phytochemical analysis}

The following phytochemical analysis was carried out on leaves of Hibiscus sabdariffa using the procedure of [26] as outlined below:

\section{Test for flavonoids}

$0.5 \mathrm{~g}$ of plant sample was suspended in $5 \mathrm{ml}$ of water and $2.5 \mathrm{ml}$ of methanol was added to it and filtered. $1 \mathrm{ml}$ of $\mathrm{NaOH} 10 \%$ was added to $1 \mathrm{ml}$ of the filtrate. The presence of a yellow precipitate indicated the presence of flavonoids.

\section{Test for tannins}

$7.5 \mathrm{ml}$ of water was added to plant extract $(1 \mathrm{~g})$ and heated in a water bath. It was then filtered upon cooling. Few drops of iron III chloride $\left(\mathrm{FeCl}_{3}\right)$ 0.5\% were added to $2 \mathrm{ml}$ of the filtrate. The appearance of a green or dark-blue precipitate indicated the presence of tannins.

\section{Test for alkaloids}

$2 \mathrm{~g}$ of plant sample was heated in a test tube containing $25 \mathrm{ml}$ of $\mathrm{HCl}(1 \%)$ for $15 \mathrm{~min}$ in a boiling water bath. The suspension was then filtered and 5 drops of Meyer's reagent (potassium tetra iodomecurate) were added into 
the filtrate $(1 \mathrm{ml})$. The formation of a precipitate indicated the presence of alkaloids.

\section{Test for saponins}

$0.5 \mathrm{~g}$ of plant extract was introduced into a test tube containing $7.5 \mathrm{ml}$ of distilled water and the mixture heated for $5 \mathrm{~min}$ in a boiling water bath. The solution was then filtered and cooled to room temperature. Five millilitres of the filtrate was introduced into a test tube and agitated for $10 \mathrm{~s}$. The formation of persistent foam indicated the presence of saponins.

\section{Test for triterpenes and steroids}

$0.5 \mathrm{~g}$ of plant sample was dissolved in chloroform $(3 \mathrm{ml})$ and a few drops of acetic anhydride and concentrated $\mathrm{H}_{2} \mathrm{SO}_{4}$ were added. A purple coloration indicated the presence of triterpenes while bluish-green coloration indicated the presence of steroids. The formation of two layers upon addition of $\mathrm{H}_{2} \mathrm{SO}_{4}$ is characteristic of the presence of both triterpenes and steroids.

\section{Test for coumarins}

One milligram of moistened sample was placed in a test tube and the test tube was covered with a filter paper moistened with $10 \% \mathrm{NaOH}$ solution. After exposition of the paper to UV light for a few minutes, yellow green fluorescence was indicative of the presence of coumarins

\section{Acute toxicity study}

Rats fasted for $16 \mathrm{~h}$ were randomly divided into seven groups of five rats each. One group served as control and received $0.3 \mathrm{mls}$ of distilled water orally. The other groups (test groups) were treated with graded doses of HSCE; 200, 400, 800, 1600, 3200 and $6400 \mathrm{mg} \mathrm{kg}^{-1}$ dissolved in distilled water orally. Signs of toxicity (convulsion, hypoactivity, weakness, ataxia and salivation) and mortality in each cage were assessed 24 hours, 48 hours and 72 hours after administration of extract. $\mathrm{LD}_{50}$ of HSCE was determined in the rats using method of Abdel-Barry et al. [27].

\section{Induction of experimental diabetes}

Animals were fasted (but still allowed access to water) for 16 hours prior to induction. Diabetes mellitus was induced in groups $\mathrm{C}, \mathrm{D}$ and $\mathrm{E}$ rats by a single i.p. injection of $80 \mathrm{mg} / \mathrm{kg}$ bw STZ dissolved in $0.1 \mathrm{M}$ sodium citrate buffer (pH 6.3) as previously reported [28,29]. Group A rats were injected with equivalent volumes of citrate buffer i.p.

\section{Administration of drugs}

Four weeks post induction of diabetes, daily doses of $1750 \mathrm{mg} / \mathrm{kg}$ bw HSCE was administered orally to the rats in test groups I and II (groups B and D) for 15 days by gavage while $1 \mathrm{IU} / \mathrm{kg} /$ day of protamine zinc insulin was administered i.p. to group $\mathrm{E}$ rats (diabetic positive control). Rats in group C (diabetic negative control) were left untreated.

\section{Terminal sacrifice procedures}

A mid-line incision was made through the anterior abdominal walls of the rats under terminal chloroform anaesthesia. The liver tissues were excised and weighed. Some of the liver tissues were fixed in in $10 \%$ formol saline for 48 hours for histological procedures, some fixed in Bouin's fixative for 24 hours for histochemical procedure while other parts were frozen for biochemical assay.

\section{Determination of liver weight}

At sacrifice, the absolute liver weight was determined using a top loader sensitive balance (Mettler Toledo Germany). The relative weight of the liver (\%) was calculated from the body weight at sacrifice and the absolute liver weights as previously described [29].

$$
\text { Relative weight of the liver }=\frac{\text { Absolute weight }}{\text { body weight at sacrifice }} \times 100
$$

\section{Histological procedure}

Liver tissues fixed in 10\% formol saline were processed via paraffin wax embedding method [30]. Sections of $5 \mu \mathrm{m}$ thickness produced were stained with haematoxylin and eosin (HE) for general histological examination of the liver tissues, Gordon and Sweets reticulin stain (GSR) [31] to histologically demonstrate reticulin fibres in the liver and with Masson trichrome stain (MT) to histologically demonstrate collagen fibres in liver. The sections were examined under Leica DM750 research microscope with a digital camera (Leica ICC50) attached. Digital photomicrographs were taken at various magnifications.

\section{Histochemical procedure}

The tissues fixed in Bouin's fixative were processed via paraffin wax embedding. Sections of $5 \mu \mathrm{m}$ thickness produced were stained with periodic acid Schiff (PAS) with diastase control to histochemically demonstrate glycogen in the liver sections. Digital photomicrographs were also taken after examination under Leica DM750 research microscope

\section{Biochemical assays}

\section{Assay for liver function markers}

Blood samples were obtained from the rats by cardiac puncture at sacrifice and were kept for $30 \mathrm{~min}$ at room temperature. Serum was separated from the blood samples by centrifugation at $5000 \mathrm{rpm}$ for $10 \mathrm{~min}$ at 
room temperature. Serum marker of liver function such as such as aspartate amino transferase (AST) alanine amino transferase (ALT) and alkaline phosphatase (ALP) as well as serum total proteins (TP) and albumin (ALB) were estimated spectrophotometrically, using enzymatic colorimetric assay kits (Randox, Northern Ireland) following standard methods.

\section{Preparation of tissue homogenates}

The excised livers were cut into separate portions for estimation of catalase (CAT), superoxide dismutase (SOD), glutathione peroxidase (GPX), glutathione (GSH) and thiobarbituric reactive subatances (TBARS). Tissues were rinsed in ice rinsed in ice-cold phosphate buffered saline $\mathrm{pH}$ 7.4. The tissues were then homogenized at $4^{\circ} \mathrm{C}$ in five volumes of homogenizing buffer per gram of tissue using a motor driven glass-Teflon Potter-Elvejhem homogenizer. The homogenizing buffer for CAT and GPX assay contained $50 \mathrm{mM}$ tris $\mathrm{HCl} \mathrm{pH} \mathrm{7.5,5 \textrm {mM }}$ EDTA and $1 \mathrm{mM}$ dithiotreitol (DTT); SOD assay homogenizing buffer contained $50 \mathrm{mM}$ sucrose, $200 \mathrm{mM}$ mannitol and $1 \mathrm{mM}$ EDTA prepared in $10 \mathrm{mM}$ Tris buffer $\mathrm{pH}$ 7.4.; GSH assay homogenizing buffer contained $50 \mathrm{mM}$ potassium phosphate (PH 7.0) and $1 \mathrm{mM}$ EDTA while the homogenizing buffer for TBARS Assay was a radio-immuno precipitation assay (RIPA) buffer which contained $150 \mathrm{mM}$ sodium chloride, $50 \mathrm{mM}$ tris buffer $\mathrm{pH} 8.0,1.0 \%$ triton $\mathrm{X}-100,0.1 \%$ sodium duodecyl sulphate (SDS) and $0.5 \%$ sodium deoxycholate. The homogenates were centrifuged in Harrier 15/80 MSE ultracentrifuge at $13,000 \mathrm{rpm}$ for 15 minutes to obtain the supernatant.

Biochemical assay for antioxidants and lipid peroxidation markers

The activities of CAT, SOD and GPX as well as the concentration of GSH and TBARS were determined in the resulting supernatants by a 96-well microplate-based assay using their specific quantitative colorimetric detection kits following manufacturers manual. Assay for catalase activity was based on catalase degradation of hydrogen peroxide using a redox dye [32]; the activity of glutathione peroxidase was measured in the tissue homogenates by measuring NADPH consumption in the enzyme-coupled reaction [33]; the activity of SOD was measured using sensitive colorimetric SOD assay kit which utilizes water soluble tetrazolium salt (WST-1) that produces a water-soluble formazan dye upon reduction with superoxide anion [34]; concentration of glutathione was measured based on the reaction of 5, 5'- dithiobis 2-nitrobenzoic acid (DTNB) with reduced glutathione to form a yellow product [35] while TBARS assay was based on the reaction of TBARS with thiobarbituric acid (TBA) to form a pink coloured product [36].

\section{Statistical analysis}

All values were presented as mean \pm standard error of mean (SEM) for twelve rats in each of the five group of rats. The significance of difference in the means of all parameters was determined using one-way analysis of variance (ANOVA; 95\% confidence interval). Dunnett multiple comparison (DMC) and Student NewmanKeul's (SNK) post hoc tests were carried out for comparison of all groups with control and comparison of all pairs of groups respectively. All statistics were carried out in GraphPad Prism. Values of $\mathrm{p}<0.05$ were considered as significant [37].

\section{Results}

\section{Acute toxicity}

No sign of toxicity was observed in all groups of animals tested within 72 hours. The $\mathrm{LD}_{50}$ of $H$. Sabdariffa in Wistar rats was found to be $3200 \mathrm{mg} \mathrm{kg}^{-1}$.

\section{Effects of HSCE on liver weight}

The effects of HSCE on the body weight, absolute and relative liver weight in all groups of rats are shown in Table 1. The diabetic positive and negative controls presented with severe loss in body weight and absolute liver weight when compared with the other groups. However the relative weight of the liver with respect of the body weight was essentially similar in all groups.

\section{Effects of HSCE on liver function markers}

The activities of alanine amino transferase (ALT), aspartate amino transferase (AST) and alkaline phosphatase

Table 1 Effects of $\boldsymbol{H}$. Sabdariffa on body weight and liver weight

\begin{tabular}{lccc}
\hline & Body weight (g) & Absolute liver weight (g) & Relative liver weight (\%) \\
\hline A (normal control) & $181.92 \pm 6.49^{\dagger}$ & $7.83 \pm 0.64^{\dagger}$ & $4.31 \pm 0.33^{\dagger}$ \\
B (Test I) & $179.75 \pm 7.11^{\dagger}$ & $7.93 \pm 0.68^{\dagger}$ & $4.41 \pm 0.35^{\dagger}$ \\
C (Diabetic -ve control) & $141.58 \pm 3.33^{* \neq}$ & $5.17 \pm 0.51^{* \neq}$ & $3.66 \pm 0.29^{\dagger}$ \\
D (Test II) & $168.17 \pm 6.15^{\dagger}$ & $7.02 \pm 0.57^{* \S}$ & $4.17 \pm 0.32^{\dagger}$ \\
E (Diabetic + ve control) & $139.41 \pm 2.55^{* \neq}$ & $5.08 \pm 0.43^{* \neq}$ & $3.64 \pm 0.31^{\dagger}$ \\
\hline
\end{tabular}

${ }^{*} \mathrm{p}<0.05$ compared with the normal control, determined by one way ANOVA followed by DMC post hoc test.

${ }^{\dagger \neq \S}$ within column signifies $\mathrm{p}<0.05$ between groups with different symbols, determined by SNK post hoc test. 
Table 2 Effects of $\boldsymbol{H}$. Sabdariffa on the liver function markers

\begin{tabular}{lcrr}
\hline & AST (U/L) & ALT (U/L) & ALP (U/L) \\
\hline A (normal control) & $11.38 \pm 2.46^{\dagger}$ & $10.72 \pm 1.64^{\dagger}$ & $85.13 \pm 7.08^{\dagger}$ \\
B (Test I) & $12.05 \pm 2.36^{\dagger}$ & $10.63 \pm 0.33^{\dagger}$ & $78.62 \pm 5.28^{\dagger}$ \\
C (Diabetic -ve control) & $45.72 \pm 5.28^{* \neq}$ & $54.05 \pm 5.03^{* \neq}$ & $181.94 \pm 12.12^{* \neq}$ \\
D (Test II) & $14.68 \pm 1.64^{\dagger}$ & $12.08 \pm 2.42^{\dagger}$ & $103.21 \pm 6.98^{* \S}$ \\
E (Diabetic + ve control) & $37.33 \pm 5.15^{* \S}$ & $43.12 \pm 4.16^{* \S}$ & $149.06 \pm 9.12^{* \neq}$ \\
\hline
\end{tabular}

* $p<0.05$ compared with the normal control, determined by one way ANOVA followed by DMC post hoc test.

${ }_{+\neq \$ \ddagger}$ within column signifies $\mathrm{p}<0.05$ between groups with different symbols, determined by SNK post hoc test.

in normoglycemic, diabetic negative and positive controls and extract treated groups are presented in Table 2. The activities of AST, ALT and ALP significantly increased $(\mathrm{p}<0.05)$ in the diabetic negative and positive control rats when compared with the normoglycemic rats. The activities of these liver marker enzymes were significantly lowered in Test group II rats. However, $H$. Sabdariffa had no effect on the activity of these enzymes in normal rats.

\section{Effects of HSCE on serum proteins}

Elevated concentrations of TP and GLB in diabetic negative control rats were brought down significantly $(\mathrm{p}<0.05)$ following administration of HSCE and insulin (Table 3). In addition albumin - globulin ratio which was significantly lower $(\mathrm{p}<0.05)$ in the diabetic negative control group compared with normoglycemic rats was significantly raised in the diabetic positive control and test group II.

\section{Effects of HSCE on liver antioxidants}

The activities of the antioxidant enzymes (catalase, superoxide dismutase and glutathione peroxidase) and the concentration of glutathione (a non-enzymatic antioxidant) were significantly lower $(\mathrm{p}<0.05)$ in the liver of the diabetic negative control rats compared with normoglycemic rats (Table 4). HSCE treatment elevated the activities of these antioxidant enzymes and concentration of glutathione significantly $(\mathrm{p}<0.05)$ in the liver of test group II rats better than that demonstrated by protamin zinc insulin in the diabetic positive control group (Table 4). However HSCE treatment had no significant effects on these antioxidants in the liver of normoglycemic rats.

\section{Effects of HSCE on lipid peroxidation}

The concentration of TBARS, a marker of lipid peroxidation was significantly higher $(\mathrm{p}<0.05)$ in the liver of diabetic negative control rats than in normoglycemic rats (Table 4). However HSCE treatment lowered the level of TBARS significantly $(\mathrm{p}<0.05)$ in the treated rats.

\section{Histopathological assessment of the liver}

Examination of the stained sections of the liver of STZ diabetic rats revealed array of pathological changes including distortion of liver architecture, inflammation as well as necrotic changes (Figure 1), breakdown of reticulin fibres that formed supporting connective tissue of the liver (Figure 2), accumulation of collagen fibres in areas where reticular fibres are broken down (Figure 3) and excessive deposition of glycogen (Figure 4). These pathological changes which persisted in rats treated with protamin zinc insulin were absent in the liver section of diabetic rats treated with HSCE. However, HSCE had no effects on the liver of normal rats.

\section{Discussion}

Diabetes mellitus is associated with progressive metabolic derangement, worsening glycaemic control and morphological changes in the kidney, retina, liver, pancreas and

Table 3 Effects of $\boldsymbol{H}$. Sabdariffa on the serum proteins

\begin{tabular}{lcccc}
\hline & Total protein (g/d) & Albumin (g/d) & Globulin (g/dl) & Albumin/globulin ratio \\
\hline A (normal control) & $8.19 \pm 0.36^{\dagger}$ & $4.26 \pm 0.42^{\dagger}$ & $3.93 \pm 0.31^{\dagger}$ & $1.08 \pm 0.18^{\dagger}$ \\
B (Test I) & $8.25 \pm 0.26^{\dagger}$ & $4.05 \pm 0.18^{\dagger}$ & $4.20 \pm 0.26^{\dagger}$ & $0.96 \pm 0.21^{\dagger}$ \\
C (Diabetic -ve control) & $13.28 \pm 0.68^{* \dagger}$ & $4.12 \pm 0.79^{\dagger}$ & $9.16 \pm 0.56^{* \neq}$ & $0.49 \pm 0.06^{* \neq}$ \\
D (Test II) & $7.95 \pm 0.19^{\dagger}$ & $3.86 \pm 0.24^{\dagger}$ & $4.09 \pm 0.41^{\dagger}$ & $0.95 \pm 0.11^{\dagger}$ \\
E (Diabetic + ve control) & $8.21 \pm 0.15^{\dagger}$ & $3.93 \pm 0.65^{\dagger}$ & $4.28 \pm 0.12^{\dagger}$ & $0.92 \pm 0.13^{\dagger}$ \\
\hline
\end{tabular}

${ }^{*} p<0.05$ compared with the normal control, determined by one way ANOVA followed by DMC post hoc test.

${ }^{t \neq}$ within column signifies $p<0.05$ between groups with different symbols, determined by SNK post hoc test. 
Table 4 Effects of $\boldsymbol{H}$. Sabdariffa on the liver antioxidants and lipid peroxidation markers

\begin{tabular}{|c|c|c|c|c|c|}
\hline & CAT (U/L) & GPx (U/L) & SOD $(\mathrm{U} / \mathrm{mL})$ & GLU $(\mu \mathrm{M})$ & TBARS $(\mu \mathrm{M} M D A)$ \\
\hline A (normal control) & $1.04 \pm 0.07^{\dagger}$ & $1.71 \pm 0.06^{\dagger}$ & $101.42 \pm 6.11^{\dagger}$ & $8.97 \pm 0.71^{\dagger}$ & $7.79 \pm 0.72^{+}$ \\
\hline B (Test I) & $1.09 \pm 0.06^{\dagger}$ & $1.67 \pm 0.08^{\dagger}$ & $95.04 \pm 6.56^{\dagger}$ & $7.78 \pm 0.67^{\dagger}$ & $7.12 \pm 0.46^{\dagger}$ \\
\hline C (Diabetic -ve control) & $0.42 \pm 0.04^{*}$ & $0.86 \pm 0.06^{* \neq}$ & $41.08 \pm 3.04^{* \neq}$ & $3.76 \pm 0.38^{*}$ & $17.56 \pm 1.02^{* \S}$ \\
\hline D (Test II) & $0.72 \pm 0.06^{*}$ & $1.37 \pm 0.06^{* \S}$ & $87.92 \pm 5.26 \S$ & $6.87 \pm 0.51^{\dagger}$ & $8.63 \pm 0.65^{\dagger}$ \\
\hline E (Diabetic + ve control) & $0.37 \pm 0.03^{* \neq}$ & $0.97 \pm 0.05^{*} \neq$ & $46.58 \pm 3.57^{* \neq}$ & $3.26 \pm 0.39^{* \neq}$ & $11.56 \pm 0.73^{* \neq}$ \\
\hline
\end{tabular}

*p $<0.05$ compared with the normal control, determined by one way ANOVA followed by DMC post hoc test.

${ }_{t \neq \S \neq}$ within column signifies $\mathrm{p}<0.05$ between groups with different symbols, determined by SNK post hoc test.

other organs [38,39]. Oxidative stress is known to play a significant role in the induction of these processes [40]. A number of studies both in vitro and in vivo had shown that extracts of the calyx of $H$. sabdariffa has potent antioxidant activity [41,42]. This potent antioxidation is thought to form the basis of many of the other healing activities of HSCE including its hepatoprotective activities. Compounds proven to have this antioxidant activity include anthocyanins and protocatechuic acid [43].

The results of this study showed a significant increase in lipid peroxidation in the liver of STZ diabetic rats. This confirms the earlier report on the ability of this diabetogenic compound to induce oxidative damage through
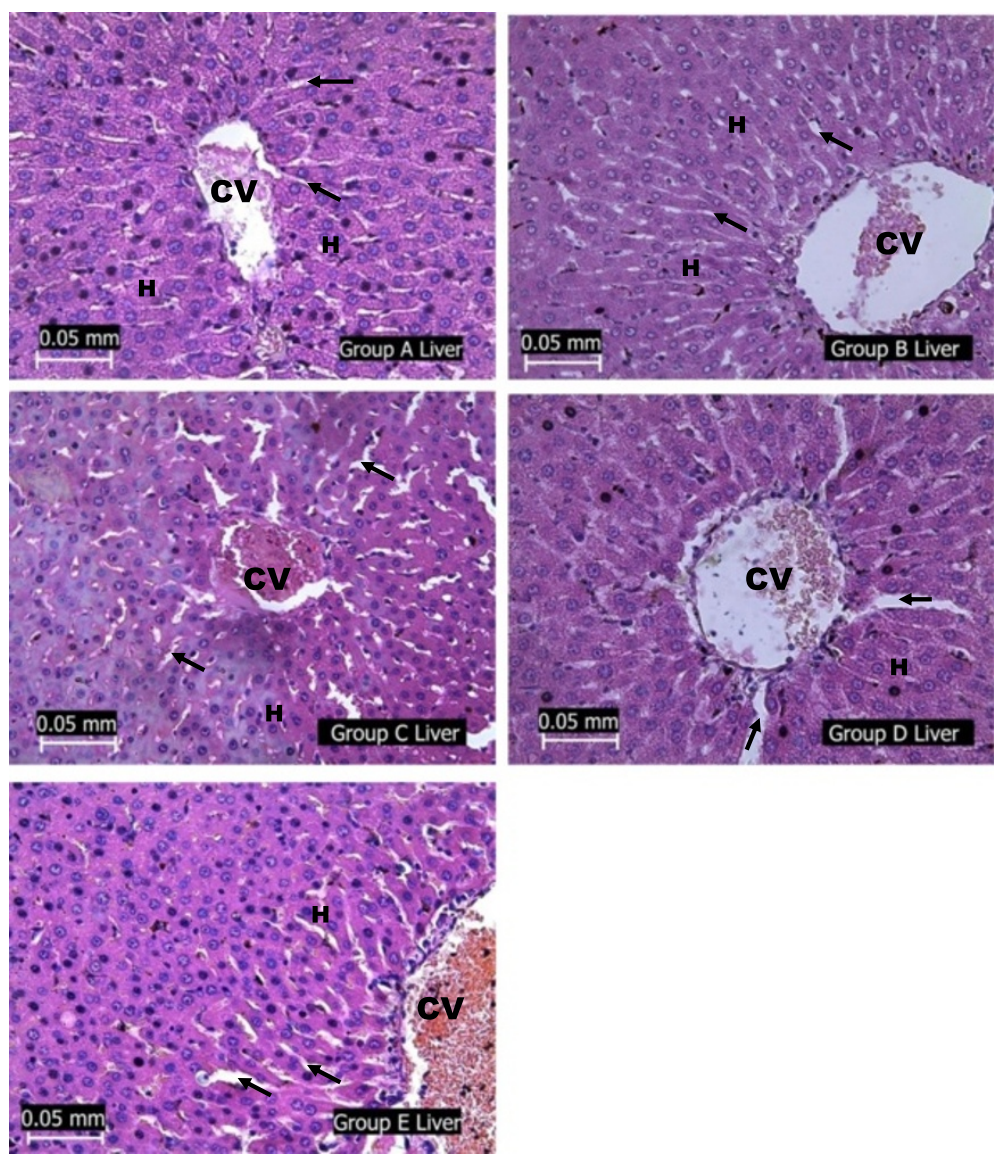

Figure 1 Photomicrographs showing the liver of the experimental rats (A - normoglycaemic rats, B - test group I, C - diabetic negative control, D - test group II and E - diabetic positive control) stained with $\mathbf{H}$ \& E. Note the hepatocytes $(\mathrm{H})$ arranged in plates around the central vein (CV) with sinusoids (arrow) in between the plates. Architecture of groups A B and D liver appeared normal. Distortion of architecture and signs of inflammation were observed in group C liver while group E liver section revealed a disheveled pattern of liver architecture with poorly defined hepatocytes and sinusoids except those in the immediate vicinity of the central vein. Vascular congestion of the central vein was also observed in the liver of group $C$ and $E$ rats. 

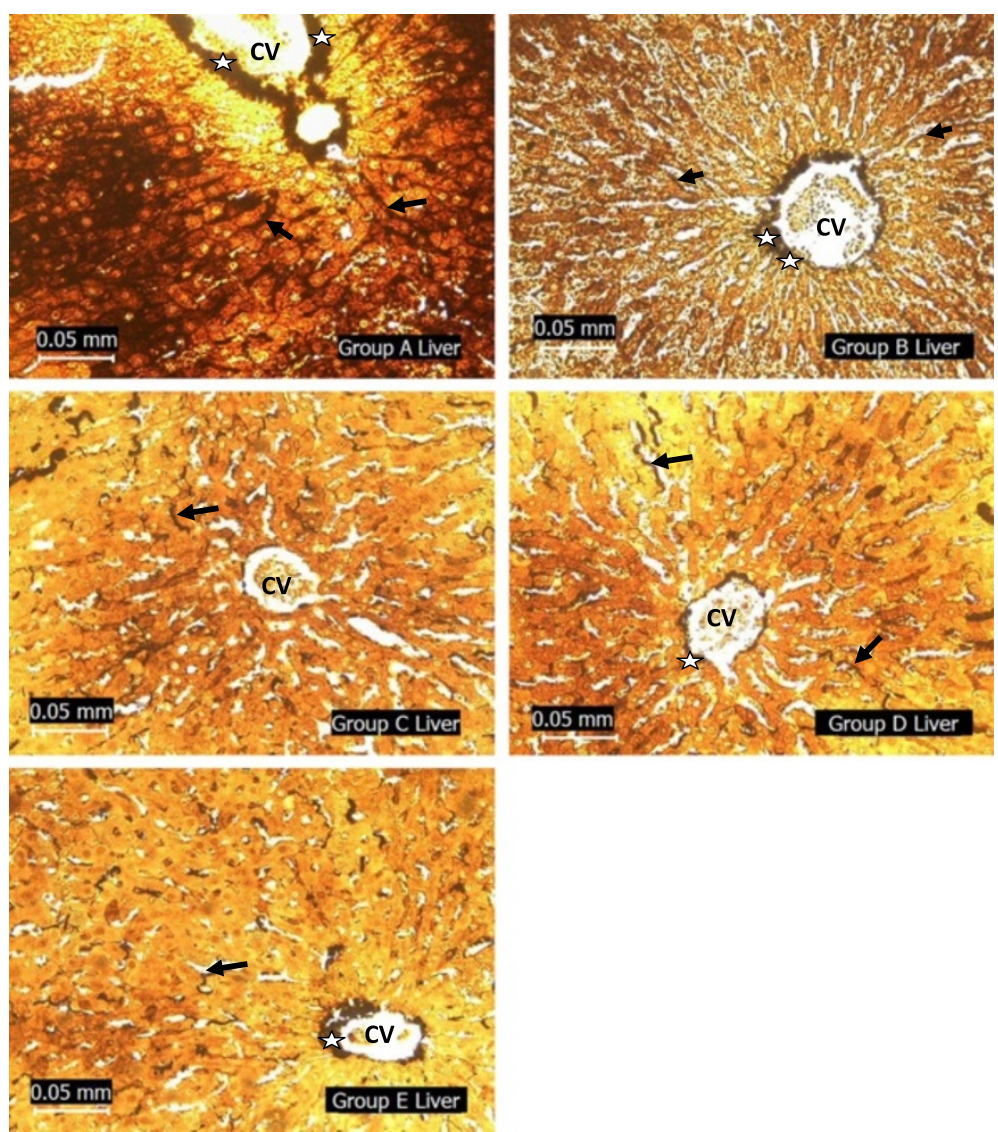

Figure 2 Photomicrographs showing the liver of the experimental rats (A - normoglycaemic rats, B - test group I, C - diabetic negative control, D - test group II and E - diabetic positive control) stained with Gordon and Sweets reticulin stain. Note the reticular fibres (stained black) lining the sinusoids (arrow) where they are between plates of liver cells (stained yellow) and also form a dense network (star) around the central vein (CV). The reticular fibres are well stained in the liver section of groups A, B and D rats. However, in groups C and E liver, the reticular fibres are poorly stained except where they form dense network around the central vein.

generation of free radicals [44]. The increase in lipid peroxidation in the liver may be due to the fact that it contains relatively high concentration of easily peroxidizable fatty acid. Administration of methanolic extract of $H$. sabdariffa reduced MDA, a marker of lipid peroxidation in the liver of diabetic rats suggesting that the extract possesses potent antioxidative properties. The present results are consistent with the report of previous researchers who earlier reported antioxidant effect of extracts from $H$. sabdariffa [41].

In this study, a marked decrease in the activities of catalase (CAT), superoxide dismutase (SOD) and glutathione peroxidase (GPx) in the liver of untreated diabetic rats were observed. The functions of these antioxidant enzymes are interconnected and a decrease of their activities results in the accumulation of lipid peroxides and increases oxidative stress in diabetic rats [45]. Treatment of rats with extracts of $H$. sabdariffa ameliorated the STZ-induced decrease in the concentration of GSH as well as the activities of GPx, SOD and CAT. The results, therefore, lend support to the antioxidant properties of $H$. sabdariffa as demonstrated in both in vitro and various in vivo models $[41,46]$.

Hepatic cellular degeneration, degeneration of reticular fibres as shown in the silver impregnated liver section (Figure 2) and build up of collagen fibres as shown in the liver sections stained for presence of collagen (Figure 3) revealed the presence of hepatic fibrosis in the liver of STZ-diabetic rats and the insulin treated diabetic rats. The PAS stained sections also revealed an excessive accumulation of glycogen in the liver of the diabetic rats (Figure 4). However, there was restoration of the normal liver morphology in the $H$. sabdariffa - treated diabetic rats. This was shown by a regeneration of reticular fibres as well as reduction in the collagen staining in the liver section of the extract-treated rats. Also, PAS - stained liver section of this group of rats' reveled glycogen staining that is 


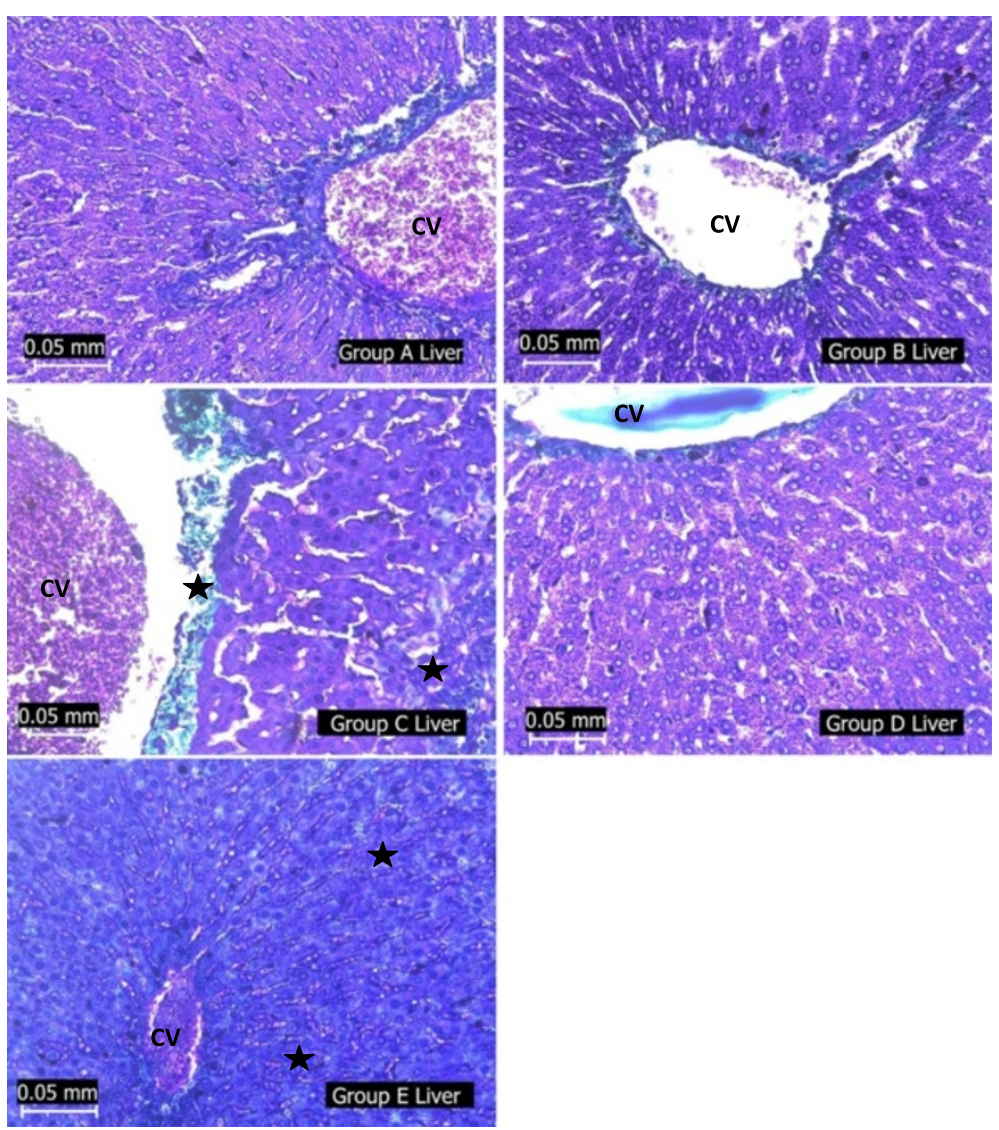

Figure 3 Photomicrographs showing the liver of the experimental rats (A - normoglycaemic rats, B - test group I, C - diabetic negative control, D - test group II and E - diabetic positive control) stained with Masson trichrome stain. Note extensive area of collagen staining (black star) around the CV as well as the intercellular matrix around the hepatocytes of the liver groups C and E rats.

comparable with that of the normal rats. Histopathological evaluation of the liver of these rats also revealed that $H$. sabdariffa extract also reduced the incidence of liver lesions, including hepatocyte swelling and necrosis induced by STZ.

Hepatic fibrosis is present in various chronic hepatic diseases. It is well known that constant fibrosis can lead to the development of hepatocellular carcinoma $[47,48]$. Interrupting and/or reversing hepatic fibrosis may well be a new approach for improving its progression to hepatocellular carcinoma. However, the therapy for reversing liver fibrosis is not yet well established. This study demonstrated that $H$. sabdariffa extract had therapeutic effects on hepatic fibrosis secondary to diabetes induced by STZ in rats. The beneficial effects of $H$. sabdariffa extract in the treatment of chemicallyinduced fibrosis were evident in liver pathology, as evidenced by decreased severity of the liver morphological changes and fibrosis, generalized improvement of some types of pathological lesions such as fatty liver and cellular degeneration, and reduced hepatic collagen fiber staining. These ameliorative effects of $H$. sabdariffa extract may be mediated by inhibition of hepatic stellate cell activation. In accord with the preventive effects of $H$. sabdariffa extract's components during the development of chemically induced hepatic damage $[20,21,43,49]$ the present study shows that $H$. sabdariffa extract is effective in the amelioration of STZ-induced liver fibrosis, which would confer a highly significant therapeutic advantage. $\mathrm{Hi}$ biscus sabdariffa extract is a composite of several antioxidants, such as protocatechuic acid [20,50] and anthocyanins [21,22] which prevents peroxidative liver damage.

The activities of AST, ALT and APL increased significantly in diabetic rats in agreement with previous findings [51]. The extract of $\mathrm{H}$ sabdariffa significantly reduced the activities of AST and ALT in these rats. This finding is consistent with the finding of Ubani et al. [52] who earlier reported that extract of $H$. sabdariffa lowered the activities of these liver marker enzymes in phenobarbitone induced rats. 

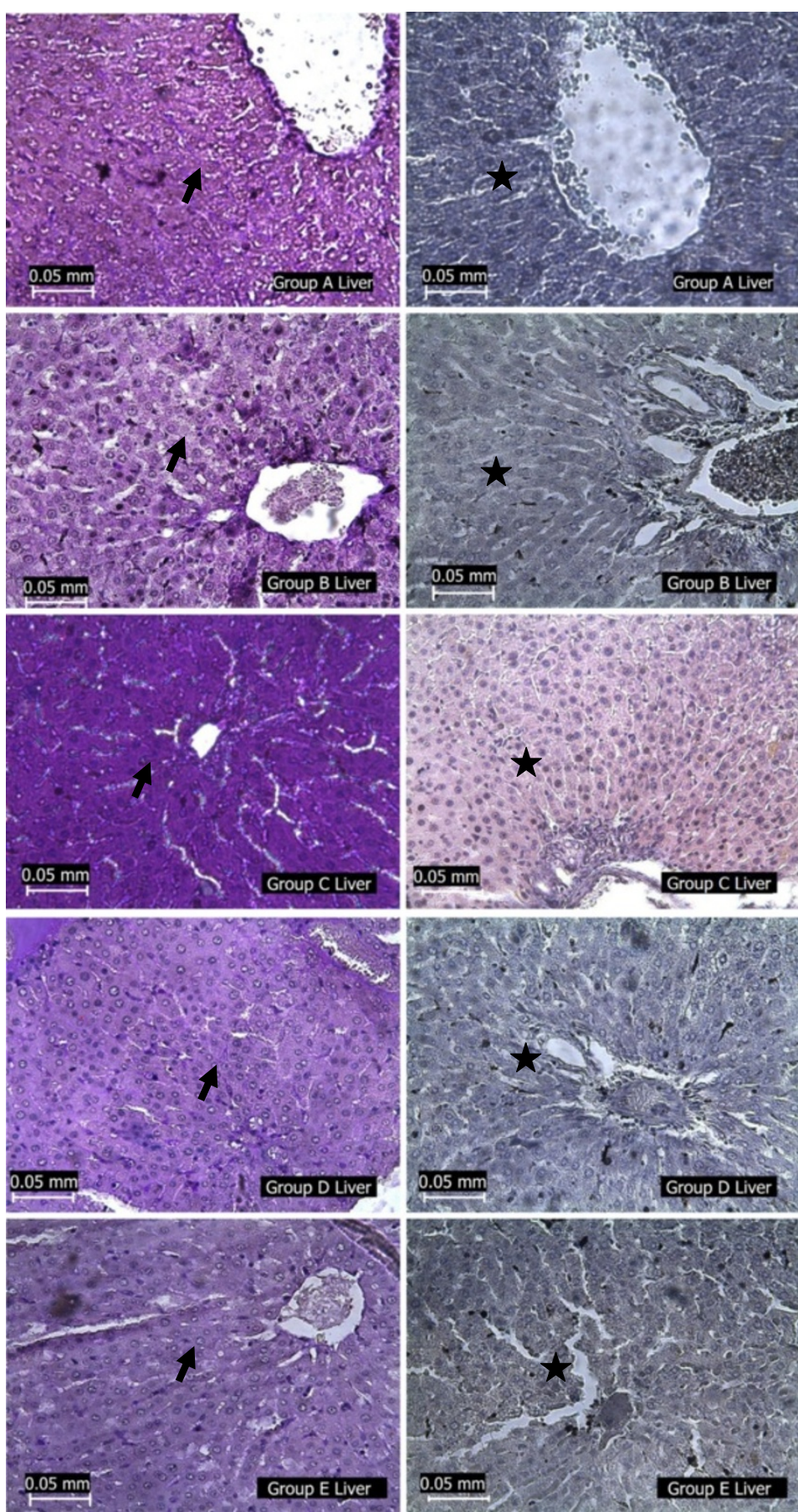

Figure 4 Photomicrographs showing the liver of the experimental rats (A-normoglycaemic rats, B- test group I, C-diabetic negative control, D test group II, E-diabetic positive control) stained with PAS (arrow) with diastase control (star). The liver section of group C was deeply stained with PAS while liver sections of other groups were moderately stained with PAS. Diastase negative control was negative to PAS staining in all groups.

\section{Conclusion}

In conclusion, this study demonstrated the potentials of Hibiscus sabdariffa extract in ameliorating the biochemical and histological changes in the liver of Wistar rats following experimental induction of diabetes mellitus in these rats using STZ. The ameliorative activity of Hibiscus sabdariffa extract in the liver of STZ diabetic rats could be partly related to its antioxidant activity and the presence of flavonnoids. 


\section{Abbreviations}

HSCE: Hibiscus sabdariffa calyx extract; STZ: Streptozotocin; ip: Intraperitoneal; GSH: Glutathione; CAT: Catalase; SOD: Superoxide dismutase; GPx: Glutathione peroxidase; TBARS: Thiobarbituric acid reactive substances; AST: Aspartate amino transferase; ALT: Alanine amino transferase; ALP: Alkaline phosphatase; TP: Total protein; ALB: Albumin; GLB: Globulin; PAS: Periodic acid schiff.

\section{Competing interests}

The authors declare that they have no competing interests.

\section{Authors' contributions}

ADO; conceived the research idea, designed and executed the experiment and prepared the manuscript. EMO; supervised the biochemical aspect of the study. UVO; co-executed the experiment and review manuscript. AOS supervised the experiment in general. All authors read and approved the final manuscript.

\section{Acknowledgements}

The first Author is grateful to the authorities of Obafemi Awolowo University lle Ife for providing laboratory space and equipments for the research, Prof. C.A. Adebajo, department of Pharmacognosy for his useful suggestions and comment and to Mr Emiola Gbela (retired Chief Technologist, Department of Morbid anatomy and Forensic Medicine) for his technical assistance in the production of the microscopic slides.

\section{Author details}

${ }^{1}$ Department of Anatomy and Cell Biology, Obafemi Awolowo University, Ile-Ife, Nigeria. ${ }^{2}$ Department of Anatomy, Ekiti State University, Ado Ekiti, Ekiti State, Nigeria. ${ }^{3}$ Department of Biochemistry, Obafemi Awolowo University, lle-lfe, Nigeria.

Received: 2 April 2014 Accepted: 21 July 2014

Published: 30 July 2014

\section{References}

1. Levinthal GN, Tavill AS: Liver disease and diabetes mellitus. Clin Diabetes 1999, 17(2):73-93.

2. Subramoniam A, Pushpangadan P: Development of phytomedicine for liver diseases. Ind J Pharmacol 1999, 31:166-175.

3. Muhtaseb MS, El Talwar D, Duncan A, St J, O'reilly D, Mckee RF, Anderson $\mathrm{JH}$, Foulisa FIG: Free radical activity and lipid soluble anti-oxidant vitamin status in patients with long-term ileal pouch-anal anastomosis. Colorectal Dis 2008, 11:67-72.

4. Appiah I, Milovanovic S, Radojicic A, Nikolic-Kokic A, Orescanin-Dusic Z, Slavic M, Trbojevic S, Skrbic R, Spasic MB, Blagojevic D: Hydrogen peroxide affects contractile activity and anti-oxidant enzymes in rat uterus. $\mathrm{Br} \mathrm{J}$ Pharmacol 2009, 158:1932-1941.

5. Ishibashi H, Nakamura M, Komori A, Migita K, Shimoda S: Liver architecture, cell function, and disease. Semin Immunopathol 2009, 31:399-409.

6. Jerrold MO: Diabetes Mellitus. In Cecil Text Book of Medicine. WB Saunders; 2000:1292-1293.

7. Sanchez SS, Abregu AV, Aybar MJ, Sanchez Riera AN: Changes in liver gangliosides in streptozotocin-induced diabetic rats. Cell Biol Int 2000, 24:897-904.

8. Bolkent S, Yanardag R, Karabulut-Bulan O, Ozsoy-Sacan O: The morphological and biochemical effects of glibornuride on rat liver in experimental diabetes. Hum Exp Toxicol 2004, 23:257-264.

9. Koyuturk M, Tunali S, Bolkent S, Yanardag R: Effects of vanadyl sulfate on liver of streptozotocin-induced diabetic rats. Biol Trace Elem Res 2005, 104:233-247.

10. Stone BE, VanThiel DH: Diabetes mellitus and the liver. Sem Liver Dis 1985, 5:8-28.

11. Iwu MM, Igboko OA, Elekwa OK, Tempesta MS: Prevention of thioacetamide-induced hepatotoxicity by biflavanones of Garcinia kola. Phytother Res 1990, 4:157-159.

12. Dwivedi $Y$, Rastogi R, Garg NK, Dhawan BN: Perfusion with picroliv reverses biochemical changes induced in livers of rats toxicated with galactosamine or thioacetamide. Planta Med 1993, 59:418-420.

13. Lans CA: Ethnomedicines used in Trinidad and Tobago for urinary problems and diabetes mellitus. J Ethnobiol Ethnomed 2006, 2:45.
14. Ajay M, Chai HJ, Mustafa AM, Gilani AH, Mustafa MR: Mechanisms of the antihypertensive effect of Hibiscus sabdariffa L. calyces. J Ethnopharmacol 2007, 109(3):388-393.

15. Herrera Arellano A, Miranda Sánchez J, Avila Castro P, Herrera Alvarez S, Jiménez Ferrer JE, Zamilpa A, Román Ramos R, Ponce Monter H, Tortoriello $\mathrm{J}$ : Clinical effects produced by a standardized herbal medicinal product of Hibiscus sabdariffa on patients with hypertension. A randomized, double blind, lisinopril controlled clinical trial. Planta Med 2007. 73(1):6-12.

16. Hirunpanich $V$, Utaipat A, Morales NP, Bunyapraphatssara N, Sato $H$, Herunsale A, Suthisisang C: Hypocholesterolemic and antioxidant effects of aqueosus extracts from the dried calyx of Hibiscus sabdariffa L. in hypercholesterolemic rats. J Ethnopharmacol 2006, 103:252-260.

17. Farombi EO, Ige OO: Hypolipidaemic and antioxidant effects of ethanolic extract from dried calyx of Hibiscus sabdariffa in alloxan-induced diabetic rats. Fundam Clin Pharmacol 2007, 21(6):601-609.

18. Alarcon Aguilar FJ, Zamilpa A, Perez Garcia MD, Almanza Perez JC, Romero NE, Campos Sepulveda EA, Vazquez Carrillo LI, Roman RR: Effect of Hibiscus sabdariffa on obesity in MSG mice. J Ethnopharmacol 2007, 114(1):66-71.

19. Kim JK, So H, Youn MJ, Kim HJ, Kim Y, Park C, Kim SJ, Ha YA, Chai KY, Kim SM, Kim KY, Park R: Hibiscus sabdariffa L. water extract inhibits the adipocyte differentiation through the PI3K and MAPK pathway. J Ethnopharmacol 2007, 114(2):260-267.

20. Liu CL, Wang JM, Chu CY, Cheng MT, Tseng TH: In-vivo protective effect of protocatechuic acid on tert-butyl hydroperoxide-induced rat hepatotoxicity. Food Chem Toxicol 2002, 40(5):635-641.

21. Wang CJ, Wang JM, Lin WL, Chu CY, Chou FP, Tseng TH: Protective effect of Hibiscus anthocyanins against tertbutyl hydroperoxide-induced hepatic toxicity in rats. Food Chem Toxicol 2000, 38(5):411-416.

22. Ali BH, Mousa HM, El-Mougy S: The effect of a water extract and anthocyanins of Hibiscus sabdariffa L. on paracetamol-induced hepatoxicity in rats. Phytother Res 2003, 17(1):56-59.

23. Olaleye MT, Joäo-Rocha BT: Acetaminophen-induced liver damage in mice: Effects of some medicinal plants on the oxidative defense system. Exp Toxicol Pathol 2008, 59(5):319-329.

24. Choi JH, Chul YC, Lee KJ, Hwang PL, Chung YC, Jeong HG: Hepatoprotective effects of an anthocyanin fraction from purple-fleshed sweet potato against acetaminophen-induced liver damage in mice. J Med Food 2009, 12(2):320-326.

25. National Research Council (NRC) Institute of Laboratory Animal Research (ILAR): Guide for the Care and Use of Laboratory Animals. 7th edition. Washington DC: National Academy Press; 1996:259.

26. Wangchuk P, Keller PA, Pyne SG, Taweechotipatr M, Tonsomboon A Rattanajak R, Kamchonwongpaisan S: Evaluation of an ethnopharmacologically selected Bhutanese medicinal plants for their major classes of Phytochemicals and biological activities. J Ethnopharmacol 2011, 137:730-742.

27. Abdel-Barry JA, Al-Hakiem MHH, Abdel-Hassan IA: Acute intraperitoneal toxicity (LD50) and target organ effects of aqueous extract of Trigonella foenumgraceum leaf in the mouse. Basrah J Sci 1997, 58:C58-C65.

28. Adeyemi DO, Komolafe OA, Adewole OS, Obuotor EM, Adenowo TK: Antihyperglycaemic activities of Annona muricata (Linn) Afr. J Trad CAM 2009, 6(1):62-69.

29. Adeyemi DO, Komolafe OA, Adewole OS, Obuotor EM, Abiodun AA, Adenowo TK: Histomorphological and morphometric studies of the pancreatic islet cells of diabetic rats treated with extracts of Annona muricata. Folia Morphol 2010, 69(2):92-100.

30. Drury RAB, Wallington EA: Carleton's Histological Technique. 5th edition. Oxford: Oxford University Press; 1980.

31. Gordon $\mathrm{H}$, Sweet $\mathrm{HH}$ : A simple method for the silver impregnation of reticulin. Am J Pathol 1936, 12:545.

32. Cowell DC, Dowman AA, Lewis RJ, Pirzad R, Watkins SD: The rapid potentiometric detection of catalase positive microorganisms. Biosens Bioelectron 1994, 9(2):131-138.

33. Pascual P, Martinez-Lara E, Bárcena JA, López-Barea J, Toribio F: Direct assay of glutathione peroxidase activity using high- performance capillary electrophoresis. J Chromatogr B Biomed Sci App/ 1992, 581:49-56.

34. Malstrom B, Andreasson L, Reinhammer B. In The Enzymes". Edited by Byer P. New York: XIIB, Academic Press; 1975:533.

35. Blenn C, Althaus FR, Malanga M: Poly (ADP-ribose) glycohydrolase silencing protects against $\mathrm{H}_{2} \mathrm{O}_{2}$-induced cell death. Biochem J 2006, 396:419-429. 
36. Ohkawa $\mathrm{H}$, Ohishi $\mathrm{N}$, Yagi $\mathrm{K}$ : Assay for lipid peroxides in animal tissues by thiobarbituric acid reaction. Anal Biochem 1979, 95:351-358.

37. Betty RK, Jonathan AC: Essential Medical Statistics. 2nd edition. USA: Blackwell science; 2003:15-409.

38. Cook MN, Girman CJ, Stein PP, Alexander CM, Holman RR: Glycaemic control continues to deteriorate after sulfonylureas are added to metformin among patients with type 2 diabetes. Diabetes Care 2005, 28:995-1000.

39. Cristina L, Roberto L, Stefano DP: $\beta$-cell failure in type 2 diabetes mellitus. Curr Diab Rep 2008, 8:179-184.

40. Baynes JW, Thorpe SR: The role of oxidative stress in diabetic complications. Curr Opin Endocrinol 1999, 3:277-284.

41. Farombi EO, Fakoya A: Free radical scavenging and antigenotoxic activities of natural phenolic compounds in dried flowers of Hibiscus sabdariffa L. Mol Nutr Food Res 2005, 49(12):11208.

42. Sáyago-Ayerdi SG, Goñi I: Hibiscus sabdariffa L: source of antioxidant dietary fiber. Arch Latinoam Nutr 2010, 60(1):79-84.

43. Liu LC, Wang CJ, Lee CC, Su SC, Chen HL, Hsu JD, Lee HJ: Aqueous extract of Hibiscus sabdariffa L. decelerates acetaminophen-induced acute liver damage by reducing cell death and oxidative stress in mouse experimental models. J Sci Food Agric 2010, 90:329-337.

44. Szkudelski T: The Mechanism of Alloxan and Streptozotocin Action in B cells of the Rat Pancreas. Physiol Res 2001, 50:536-546.

45. Panneerselvam SR, Govindasamy S: Effect of sodium molybdate on the status of lipids, lipid peroxidation and antioxidant systems in alloxan-induced diabetic rats. Clin Chim Acta 2004, 345:93-98.

46. Tseng TH, Kao ES, Chu CY, Chou FP, Lin Wu HW, Wang CJ: Protective effects of dried flower extracts of Hibiscus sabdariffa L. against oxidative stress in rat primary hepatocytes. Food Chem Toxicol 1997, 35(12):1159-1164.

47. Nissen NN, Martin P: Hepatocellular carcinoma: the high risk patient. J Clin Gastroenterol 2002, 35(Suppl. 2):S79-S85.

48. Okita K, Sakaida I, Hino K: Current strategies for chemoprevention of hepatocellular carcinoma. Oncology 2002, 62(Suppl. 1):24-28.

49. Liu JY, Chen CC, Wang WH, Hsu JD, Yang MY, Wang CJ: The protective effects of Hibiscus sabdariffa extract on $\mathrm{CCl}_{4}$-induced liver fibrosis in rats. Food Chem Toxicol 2006, 44:336-343.

50. Tseng TH, Wang CJ, Kao ES, Chu HY: Hibiscus protocatechuic acid protects against oxidative damage induced by tert-butylhydroperoxide in rat primary hepatocytes. Chem Biol Interact 1996, 101(2):137-148.

51. Hamden K, Ayadi F, Jamoussi K: Hatem Masmoudi and Abdelfattah Elfeki Therapeutic effect of phytoecdysteroids rich extract from Ajuga iva on alloxan induced diabetic rats liver, kidney and pancreas. Bio Factors 2008, 33:165-175.

52. Ubani CS, Joshua PE, Anieke UC: Effects of aqueous extract of Hibiscus sabdariffa L. calyces on liver marker enzymes of phenobarbitone-induced adult wistar albino rats. J Chem Pharm Res 2011, 3(4):528-537.

doi:10.1186/1472-6882-14-277

Cite this article as: Adeyemi et al.: Anti-hepatotoxic activities of Hibiscus sabdariffa L. in animal model of streptozotocin diabetes-induced liver damage. BMC Complementary and Alternative Medicine 2014 14:277.

\section{Submit your next manuscript to BioMed Central and take full advantage of:}

- Convenient online submission

- Thorough peer review

- No space constraints or color figure charges

- Immediate publication on acceptance

- Inclusion in PubMed, CAS, Scopus and Google Scholar

- Research which is freely available for redistribution 